\section{The establishment of injury surveillance systems in Colombia, El Salvador, and Nicaragua (2000-2006)}

\author{
Benjamin A. Sklaver, ${ }^{1}$ \\ Carme Clavel-Arcas, ${ }^{2}$ \\ Andrés Fandiño-Losada, ${ }^{3}$ \\ Maria Isabel Gutierrez-Martinez, ${ }^{3}$ \\ Julio Rocha-Castillo, ${ }^{4}$ \\ Silva Morán de García, ${ }^{5}$ \\ and Alberto Concha-Eastman ${ }^{6}$
}

Suggested citation: Sklaver BA, Clavel-Arcas C, FandiñoLosada A, Gutierrez-Martinez MI, Rocha-Castillo J, Morán de García S, et al. The establishment of injury surveillance systems in Colombia, El Salvador, and Nicaragua (2000-2006). Rev Panam Salud Publica. 2008;24(6):379-89.

Key words: developing countries, health surveillance, epidemiologic surveillance, Colombia, El Salvador, Nicaragua.

\footnotetext{
International Emergency and Refugee Health Branch, National Center for Environmental Health, Centers for Disease Control and Prevention, Atlanta, Georgia, United States of America. Send correspondence and reprint requests to: Benjamin A. Sklaver, International Emergency and Refugee Health Branch, National Center for Environmental Health, Centers for Disease Control and Prevention, 1600 Clifton Road, Mailstop F60, Atlanta, Georgia 30333, USA; telephone: 770-488-0683; fax: 770-488-3910; e-mail: bsklaver@cdc.gov

Former consultant. Pan American Health Organization, Washington, D.C., United States of America.

CISALVA Institute, Del Valle University, Cali, Colombia

Ministry of Health, Managua, Nicaragua.

Ministry of Health, San Salvador, El Salvador

6 Pan American Health Organization, Washington, D.C., United States of America.
}

\section{THE NEED FOR INJURY SURVEILLANCE}

An estimated 5.2 million people worldwide died from injuries in 2002-a mortality rate of 83 per 100000 population (1). Injuries accounted for $9 \%$ of the world's deaths in 2002 and $12 \%$ of the world's burden of disease (1). More than $90 \%$ of deaths occurred in low- and middle-income countries (2). Consequently, injuries are a major public health problem throughout the world and represent a leading cause of mortality and morbidity (2). Research and surveillance of the frequency, mechanisms, and outcomes of injuries in the developing world remains largely neglected (3-5).

Injury surveillance is useful for identifying high-risk groups and behaviors and assessing intervention effectiveness $(6,7)$. Although some research has been published on injury surveillance systems in developing countries, significant gaps exist concerning the establishment and maintenance of such programs $^{7}$ (8-15). Some injury surveillance systems in developing countries have relied on mortuary statistics as their data source. These systems fail to capture the disproportionate number of non-fatal injuries that occur $(16,17)$. The aim of this article is to describe key lessons learned in establishing an emergency department (ED)-based injury surveillance system in resource-poor settings.

\section{DEVELOPMENT OF INJURY SURVEILLANCE IN LATIN AMERICA}

Initial conception

The initial concept of this project was to pilot a rapid injury surveillance system that could be implemented following the cessation of armed conflict and prior to the return of refugees in war-affected regions. Having this ability would allow for critical surveillance data to be rapidly generated, analyzed, and disseminated in order to identify high-risk areas and effectively direct prevention efforts. Although the package was initially designed for violence-related injury surveillance, particularly post

\footnotetext{
Clavel-Arcas C, Chacon R, Concha-Eastman A, Espitia VE, RochaCastillo J, Soriano-Gabarro M, Suarez-Rangel G. Hospital based injury surveillance systems in Nicaragua and El Salvador, 2001-2002. Paper presented at the Seventh World Conference on Injury Prevention and Safety Promotion, Vienna, 6-9 June, 2004.
} 
conflict-related injuries from unexploded ordinance and landmines, the project was expanded in 2000 to include surveillance for all injuries.

In 2000, the Pan American Health Organization (PAHO), with technical assistance from the U.S. Centers for Disease Control and Prevention (CDC), initiated the project to establish injury surveillance systems in EDs with the goal of advancing injury epidemiology and prevention capacity in Latin America. Colombia, El Salvador, and Nicaragua were selected for the initial pilot surveillance systems, which were designed to enhance the ability of select hospitals to monitor injury trends and promote appropriate prevention interventions. The project also sought to increase injury awareness among health officials and personnel from other agencies.

\section{Data elements}

The final design for the pilot project was a sentinel surveillance system that would routinely collect a minimum set of information about the circumstances of injury events in conformity with World Health Organization (WHO)/CDC Injury Surveillance Guidelines (18). The minimum data set (MDS) employed was drawn from the International Classification of External Causes of Injury (ICECI) system (19). ICECI is a standard coding system established by $\mathrm{WHO}$ and designed to be compatible with the 10th revision of the International Classification of Diseases (ICD-10). ICECI has a multi-axial and hierarchical structure: a core module including seven items (intent, mechanism of injury, object/substance producing injury, place of occurrence, activity when injured, alcohol use, psychoactive drug or substance use), and five additional modules to enable collection of additional data on special topics (violence, transport, place, sports, occupational) (19).

The MDS for this project included sociodemographic data of the patient and general information about the injury event, such as intention, activity at the time of injury, location at the time of injury, and mechanism of injury. Specific expanded modules were developed to capture information on transport injuries (including operator activities at time of injury, vehicle involved, and safety measures employed); violent injuries (including context, relationship between perpetrator and victim, and number of perpetrators); and self-inflicted injuries (first attempt or subsequent, and precipitating factors). Modules were modified based on the specific needs and concerns of each participating country. The system also collected information on clinically suspected alcohol and illicit drug use dur- ing the physical examination when laboratory confirmation was unavailable. Clinical information collected on each patient included injury severity (mild, moderate, severe) (18); nature of the injury (e.g., fracture, laceration, and concussion); and final disposition of the injured patient (e.g., treated and released, or hospitalized). In Colombia, the Revised Trauma Score (RTS) and Glasgow Coma Scale (GCS) were used as measures rather than the injury severity scoring system described above.

To standardize data collection, a two-page ED collection form was developed (Figures 1a-b). The form collected demographic data and the MDS described above. Modules for traffic injuries, violencerelated injuries, and self-inflicted injuries were captured on the front page. The back of the form captured data on alcohol and drug use, a clinical note, nature and severity of the injury, and patient disposition. The form evolved over the six years of project implementation through ongoing input from the participating countries and analysis of the surveillance data (20). It should be noted that the two-page format of the current form inherently limits the ability of the system to collect and account for extensive pre-hospital information.

\section{Training}

Participatory methods of teaching included classroom training, interactive discussions, and practical exercises as well as site visits and regional exchange programs. The curriculum for the initial classroom training began with an overview of injury concepts and definitions, followed by basic epidemiology and surveillance techniques (Table 1).

Injury concepts discussed in the introductory lectures emphasized the burden of injuries and societal impact. Information on local and national laws related to injuries, including traffic laws, pesticide regulations, and sexual violence, was used to impress upon trainees the societal impact of injuries. Not surprising, this review frequently led to lively discussion about the potential uses of injury data to inform, enforce, and direct policy-makers. Additionally, these lectures described the reporting obligations and national health sector policies and protocols regarding care for victims of attempted suicide and violence. Training highlighted the fact that surveillance data could be used to evaluate the effectiveness of existing interventions, such as seat belt and motorcycle helmet mandates. Emphasis of the dual use of data (to both assess the quality of medical care and guide interventions) was critical for increasing trainees' understanding of the importance of epidemiologic analysis in hospitals. 
FIGURE 1a. Data collection form (page 1 of 2 ) for PAHO/CDC hospital emergency department-based injury surveillance systems in Colombia, El Salvador, and Nicaragua (2000-2006)

NAME OF HOSPIT AL. ..COUNTRY NIURY SURVEIU ANCE SYSTEM IN EMER GENCY ROOM CLINICAL REPORT IDENTIFICATION

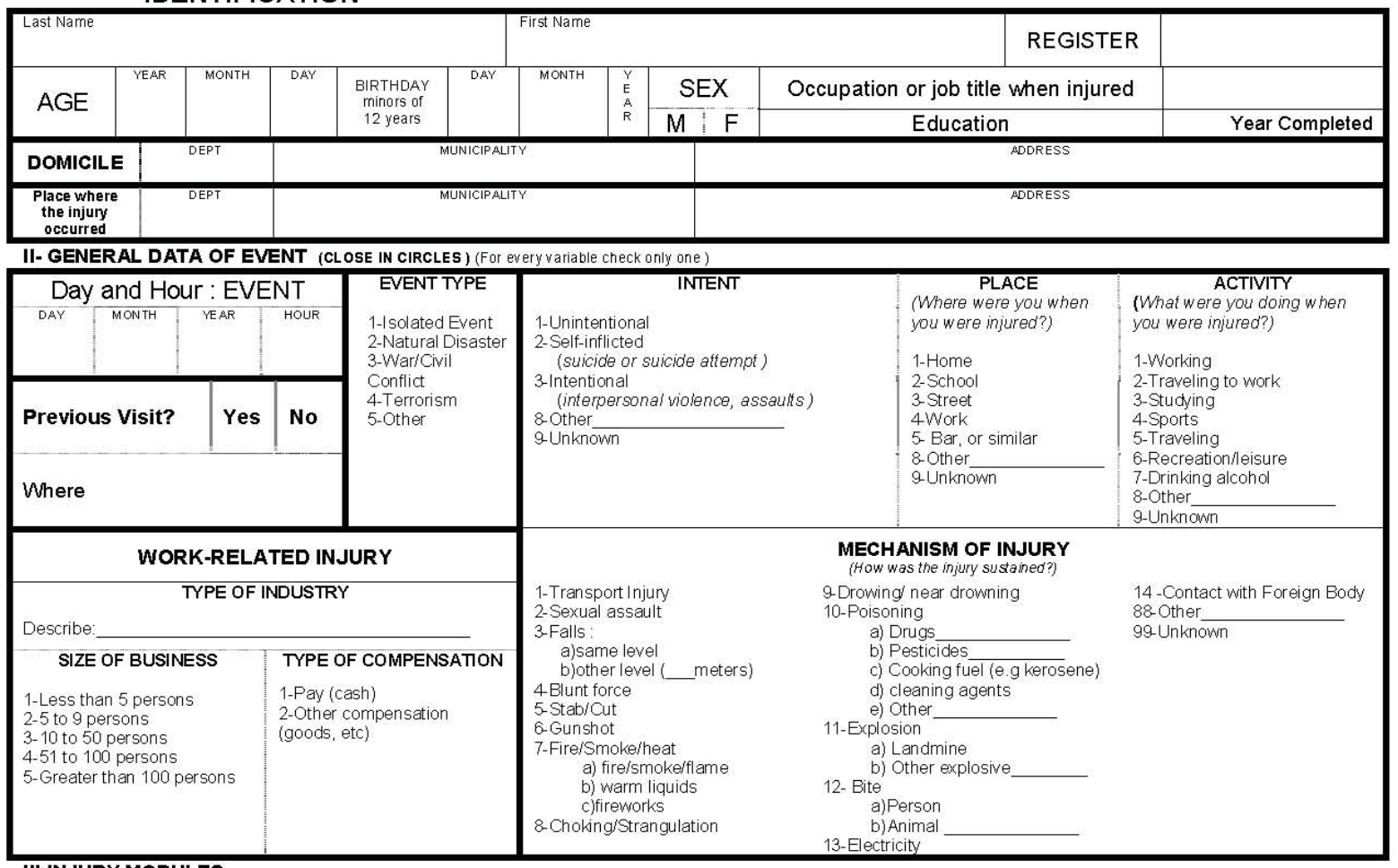

\section{III-INJURY MODULES}

\begin{tabular}{|c|c|c|c|c|c|}
\hline \multirow{2}{*}{\multicolumn{3}{|c|}{ MOTOR VEHICLE RELATED }} & \multicolumn{2}{|c|}{ INTERPERSONAL VOLENCE or ASSAULTS } & \multirow{2}{*}{$\begin{array}{l}\text { SELF-INFLICTED } \\
\text { Prior attenpt? Yes No No- }\end{array}$} \\
\hline & & & Previous episode? Yes No No-_- & Same perpetrator? Yes No & \\
\hline $\begin{array}{l}\text { MODE OF } \\
\text { TRANSPORT } \\
\text { (How was the injured } \\
\text { person traveling?) } \\
\text { 1-On foot } \\
\text { 2-Bicycle } \\
\text { 3-Motorcycle } \\
\text { 4-Car } \\
\text { 5-Pick-Up } \\
\text { 6-Truck } \\
\text { 7a-Bus } \\
\text { 7b-Microbús } \\
\text { 8-Cart/animal } \\
\text { 9-Taxi } \\
\text { 88-Other- } \\
\text { 99-Unknown - - }\end{array}$ & 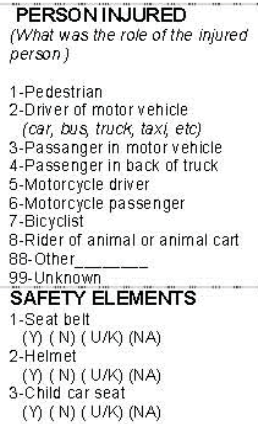 & $\begin{array}{l}\text { COUNTERPART } \\
\text { What the injured } \\
\text { person collide with? } \\
\text { 1-Pedestrian } \\
\text { 2-Bicycte } \\
\text { 3-Motorcycle } \\
\text { 4-Car } \\
\text { 5-Pick- up truck } \\
\text { 6-Large truck } \\
\text { 7a-Bus } \\
\text { 7b-Microbus } \\
\text { 8-Animal or cart } \\
\text { 9-Taxi } \\
\text { 10-Fixed Object } \\
\text { 88-Other- } \\
\text { 99-Unknown -- }\end{array}$ & $\begin{array}{l}\text { RELATIONSHIP OF } \\
\text { PERPETRATOR TO THE } \\
\quad \text { VCTMM } \\
\quad \text { (Choose only one option) } \\
\text { 1-Partner or ex-partner } \\
\text { 2a-Parent } \\
\text { 2-Step-parent } \\
\text { 3-Other relative } \\
\text { 4-Friend/Acquaintance } \\
\text { 5-Unknown person } \\
\text { 8-Other } \\
\text { 9-Unknown } \\
\text { SEX OF PERPETRATOR } \\
\text { 1-Male } \\
\text { 2-Fermale } \\
\text { 9-Unknown }\end{array}$ & $\begin{array}{l}\text { CONTEXT } \\
\text { 1-Family/Domestic violence } \\
\text { 2-QuarrevFight } \\
\text { 3- Burglary or robbery } \\
\text { 4-Sexual Assault } \\
\text { 5-Gang activity } \\
\text { 6-Stray bullet } \\
\text { - -Other } \\
\text { 9-Unknown - - }\end{array}$ & $\begin{array}{l}\text { PRECIPITATING FACTORS } \\
\text { 1-Conflict with partner/boyfriend } \\
\text { 2-Conflict with family } \\
\text { 3-Physical ilnessiproblem } \\
\text { 4-Psycological condition } \\
\text { 5-FinancialMork problems } \\
\text { 6-Legal system encounters } \\
\text { 7-Death of family member } \\
\text { 8-Victim of sexual or physical abuse } \\
\text { 9- Difficulties with school } \\
\text { 10- Unexpected pregnancy } \\
\text { 88-Other } \\
\text { 99-Unknown }\end{array}$ \\
\hline
\end{tabular}

IV- OTHER DATA ABOUT THE INJURIES

\begin{tabular}{|c|c|c|c|c|}
\hline \multicolumn{4}{|c|}{ VCTIM / INJURED PERSON (If the driver is the victim put here the information ) } & \\
\hline \multicolumn{2}{|c|}{ ALCOHOL USE } & \multicolumn{2}{|c|}{ OTHER PSYCHOACTIVE SUBSTANCE } & \\
\hline \multicolumn{5}{|c|}{ V-CLINICAL DATA } \\
\hline \multicolumn{2}{|c|}{$\begin{array}{l}\text { ANATOMIC LOCATION OF THEINUURY (IES) } \\
\text { (You can circle more than one) }\end{array}$} & \multirow{3}{*}{$\begin{array}{l}\quad \text { NATURE OF THE INJURY } \\
\text { 1-Laceration, abrasion, } \\
\text { 2-Cut } \text { Wound/Bite } \\
\text { 3- Systemic Organ Injury } \\
\text { 4-Strain/Sprain or Dislocation } \\
\text { 5-Fracture } \\
\text { 6-Burn } \\
\text { 7-Bruise, contusion } \\
\text { 8-Trauma Brain } \\
\text { 88-Others } \\
\text { 99- Unknown }\end{array}$} & \multirow[b]{2}{*}{$\begin{array}{l}\text { SEVERITY } \\
\text { 1-Minor or superficial } \\
\text { ( } 1 \text { hr b; e.g. bruises, minor cuts) } \\
\text { 2-Moderate } \\
\text { (1-4 hrs tx; e.g. fractures, sutures) } \\
\text { 3-Severe } \\
\text { ( }>4 \mathrm{hrs} \text { t } x ; \text { e.g. internal hemorrhage, } \\
\text { punctured organs, severed blood } \\
\text { vessels) } \\
\text { 4-No physical injury }\end{array}$} & \multirow[b]{2}{*}{$\begin{array}{l}\text { DISPOSITION } \\
\text { 1-Treated and discharged } \\
\text { 2-Admitted to the hospital } \\
\text { 3-Refered to other hospital } \\
\text { Which one? } \\
\text { 4Left prior to discharge } \\
\text { 5-Discharged against advice } \\
\text { 6-Died in emergency dept. } \\
\text { 7-Unknown }\end{array}$} \\
\hline \multirow[t]{2}{*}{$\begin{array}{l}\text { 1-Head } \\
\text { 2-Face } \\
\text { 2-Neck } \\
\text { 3-Eyes } \\
\text { 4-Ears } \\
\text { 5-Nose } \\
\text { 6-Thorax } \\
\text { 7-Back } \\
\text { 8-Abdomen }\end{array}$} & $\begin{array}{l}\text { 9-Pelvis/genitals } \\
\text { 10-Shoulder/Arm } \\
\text { 11-Elbow/Forearm } \\
\text { 12-Wrist'Hand/Fingers } \\
\text { 13-Hip/Thigh } \\
\text { 14-Knee/legs } \\
\text { 15-AnWl/Feet/Toes } \\
\text { 16-Multiple } \\
\text { 88-Other }\end{array}$ & & & \\
\hline & & & ICD X-DIAGNOSIS & \\
\hline
\end{tabular}


FIGURE 1b. Data collection form (page 2 of 2) for PAHO/CDC hospital emergency department-based injury surveillance systems in Colombia, El Salvador, and Nicaragua (2000-2006)

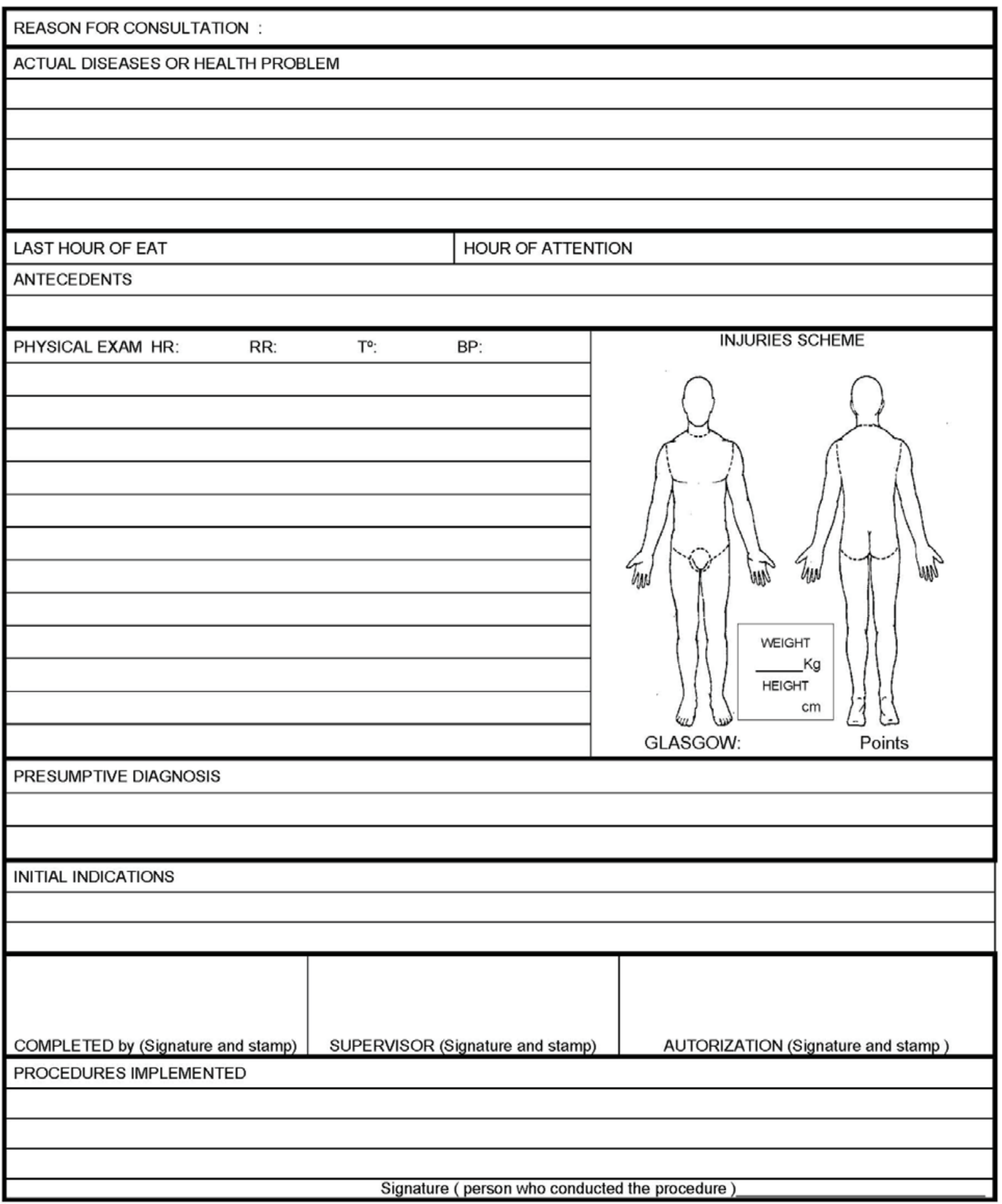

\section{Data collection protocol}

A reportable injury case was defined as a patient who was treated during their first visit for, or died from, an unintentional or violence-related injury. ED medical staff in each of the participating hospitals in the three countries were responsible for case determination and data collection (Figure 2). 
TABLE 1. Curriculum for basic injury epidemiology training for PAHO/CDC hospital emergency department-based injury surveillance systems in Colombia, El Salvador, and Nicaragua (2000-2006)

\begin{tabular}{|c|c|c|}
\hline Section & Length & Participants \\
\hline Understanding injuries & 4 hours & Doctors and interns, social workers, hospital chief \\
\hline $\begin{array}{l}\text { Establishing an emergency room injury } \\
\text { surveillance program }\end{array}$ & 4 hours & $\begin{array}{l}\text { of emergency medicine, chief of hospital, hospital } \\
\text { statisticians, representatives from hospital or local }\end{array}$ \\
\hline Basic epidemiology & 8 hours & epidemiology departments, representatives from \\
\hline $\begin{array}{l}\text { Local and national laws and protocols } \\
\text { concerning violence and injuries }\end{array}$ & 4 hours & $\begin{array}{l}\text { local health and hospital training departments, and } \\
\text { members of the National Injury Surveillance }\end{array}$ \\
\hline Epi Info ${ }^{\mathrm{TM}}$ database and analysis training & 8 hours & Committee \\
\hline Site visits and practical exercises & 12 hours & \\
\hline
\end{tabular}

ED data were collected on a standardized form for all patients who sought emergency care (Figures $1 \mathrm{a}-\mathrm{b})$; injury sections of the form were completed only for those who met the injury case definition described above. Every 24 hours, a designated individual (e.g., the hospital epidemiologist or ED charge nurse) collected and reviewed ED forms for completeness. Following the review, the attending physician was contacted to update any missing data. The hospital's epidemiological or statistical department was responsible for data entry and database management. Following data entry, the information was sent at regularly scheduled intervals by the hospital epidemiologist to the incountry project coordinator. The in-country project coordinators used an Epi Info database (Epi Info ${ }^{\mathrm{TM}}$ version 6, CDC, Atlanta, GA, USA) developed specifically for this project to monitor injury trends in each hospital and throughout the country. Periodic surveillance reports were generated and distributed to officials of participating hospitals (21), the national Ministry of Health, various nongovernmental organizations (NGOs), and National Injury Surveillance Committees (groups of representatives from governmental and nongovernmental institutions that defined objectives to guide the development of the surveillance system, and, in collaboration with PAHO/CDC, developed the data collection instrument, the Epi Info database/data analysis program, and training materials) (Figure 2). The data shared with these partners were used to guide injury prevention campaigns, including targeted interventions addressing suicide, gunpowder burns, and bicycle safety (Table 2).

\section{Monitoring and evaluation}

A PAHO/CDC project officer monitored data collection of the standard core indicators between participating countries. CDC and its external colleagues conducted a surveillance evaluation in Nicaragua using WHO/CDC Injury Surveillance Systems Guidelines (18) at the end of the first year.
Comprehensive evaluations using established evaluation guidelines $(22,23)$ were completed in 2005. These evaluations captured information related to the utility of the system, and provided a forum for presenting new ideas and mid-course improvements. In addition, in Nicaragua, annual review meetings were held among participating hospitals and the Ministry of Health to facilitate data sharing and to develop recommendations for system improvement, and the in-country PAHO/CDC project officer was available on a daily basis to answer questions about the pilot project via phone and email, providing an additional resource.

\section{Analysis of system implementation}

In an attempt to identify key lessons learned from the establishment and maintenance of the surveillance systems, the authors identified and reviewed numerous sources, including in-country workshop and meeting notes, seminar and conference proceedings, interviews with key project staff, formal evaluations and presentations of the surveillance system, and any published analyses of the surveillance data.

The authors examined records from over 20 meetings, workshops, and field visits conducted by PAHO/CDC project officers between 2000 and 2007. Included in this review were the proceedings from three regional workshops: Injury Surveillance Systems in Hospital Emergency Departments in Colombia, El Salvador, and Nicaragua (San Salvador, El Salvador, 2003); Evaluation of Hospital Injury Surveillance Systems in El Salvador, Nicaragua, and Colombia (Cali, Colombia, 2005); and Lessons Learned in Hospital-based Surveillance Systems (San Salvador, El Salvador, 2007). The authors interviewed nine representatives from the three participating countries to elicit feedback on the strengths and weakness of the project. External evaluation reports on the Nicaraguan system (2001 and 2005); El Salvadoran system (2003 and 2005); and Colombian system (2005) were reviewed. 
FIGURE 2. Data collection and flow protocol for PAHO/CDC hospital emergency department (ED)-based injury surveillance systems in Colombia, El Salvador, and Nicaragua (2000-2006)

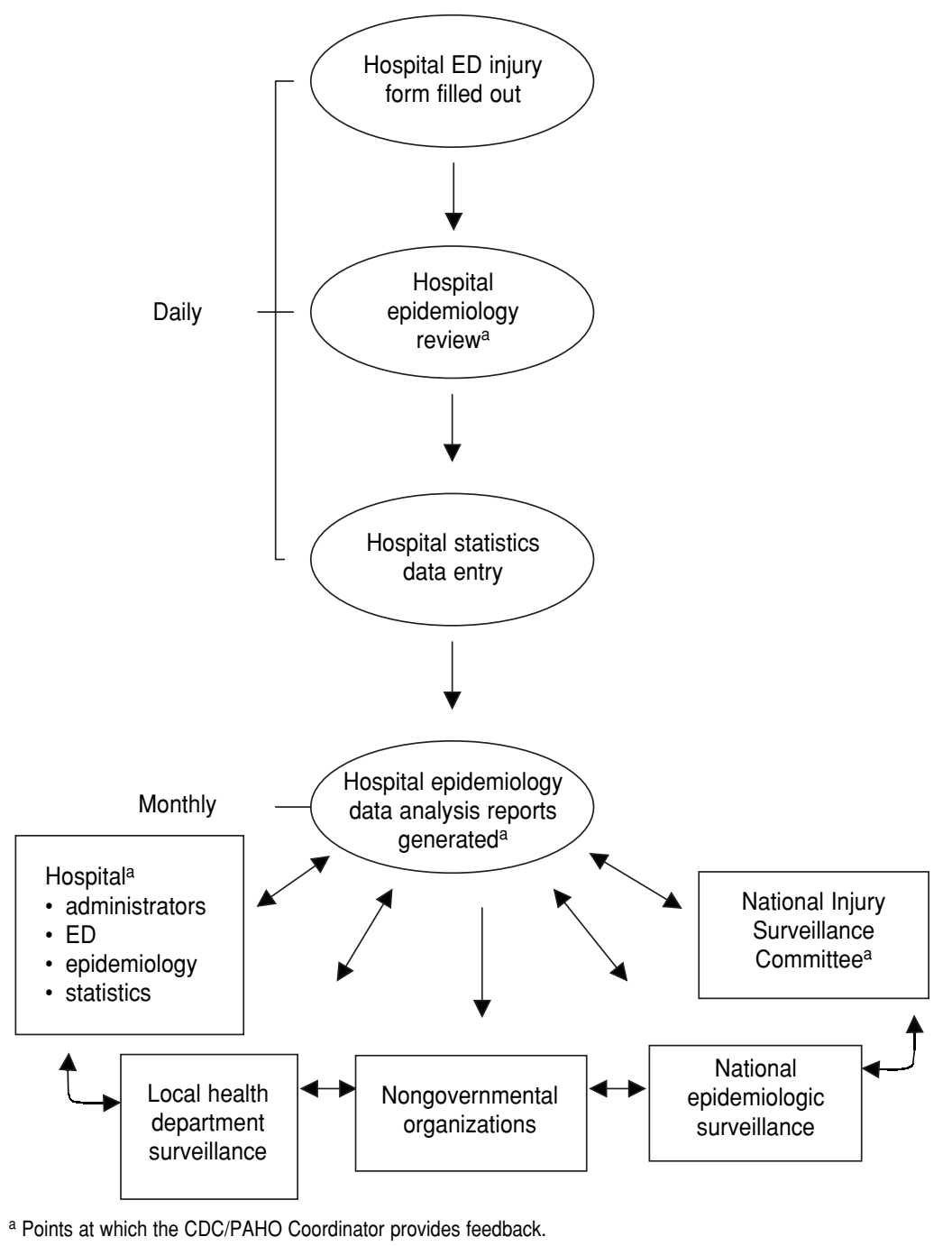

In addition, the authors examined presentations from multinational injury conferences, with a focus on identifying how data were analyzed and disseminated over time. These included presentations given at the Sixth and Seventh World Conferences on Injury Prevention and Control (Montreal, 2002, and Vienna, 2004); the First and Second Puerto Rican Public Health Conferences (San Juan, 2002 and 2004); and the CDC National Injury Prevention and Control Conference (Atlanta, 2003). The authors also abstracted and reviewed articles published in the Nicaraguan Ministry of Health's Epidemiological Bulletin (21), hospital bulletins from El Salvador (24), and journal articles from Colombia $(25,26)$.

\section{KEY LESSONS LEARNED}

A review of documents, presentations, evaluations, and personnel interviews identified several key lessons learned through six years of experience in establishing ED-based injury surveillance systems in Latin America (2000-2006). These lessons are described below.

\section{Importance of injury surveillance}

One prerequisite for a sustainable national injury surveillance system is appreciation among health officials of the national burden of injury. A 
TABLE 2. Examples of campaigns and interventions that used data from PAHO/CDC hospital emergency department-based injury surveillance systems in Colombia, El Salvador, and Nicaragua (2003-2006)

\begin{tabular}{|c|c|}
\hline Country & Campaign/Interventions \\
\hline \multirow[t]{4}{*}{ Colombia } & Road Safety Campaign \\
\hline & $\begin{array}{l}\text { In conjunction with World Health Day } 2004 \text {, CISALVA Institute and Cali Municipality worked together to alert } \\
\text { Colombians to the risk of injuries from traffic-related injuries based on data collected by the emergency } \\
\text { department (ED)-based injury surveillance system. Efforts focused on mitigating bicycle and motorcycle crashes, } \\
\text { the main cause of injuries in Cali. }\end{array}$ \\
\hline & Campaign against burns by polvora (gunpowder) in Pasto \\
\hline & $\begin{array}{l}\text { Data from the ED-based injury surveillance system collected in the Pasto Municipal Health Department were } \\
\text { used to inform the mayor about the best strategies to reduce injuries. The mayor led a } 2006 \text { multi-agency media } \\
\text { campaign against burns associated with fireworks. Data were also used to advocate for a municipal anti- } \\
\text { gunpowder regulation, which was passed in } 2006 \text {. }\end{array}$ \\
\hline \multirow[t]{6}{*}{ El Salvador } & Bicyclist Injury Prevention Plan in Nueva Concepción \\
\hline & $\begin{array}{l}\text { A multi-agency committee comprising the Ministry of Health, Ministry of Justice, police, Ministry of Transportation, } \\
\text { Office of the Mayor, nongovernmental organizations (NGOs), and high school students used data from the ED-based } \\
\text { injury surveillance system at Nueva Concepción Hospital to design a local bicyclist road-safety campaign in } 2003 .\end{array}$ \\
\hline & Campaign against burns by polvora \\
\hline & $\begin{array}{l}\text { Data from the ED-based injury surveillance system at Benjamin Bloom Pediatric Hospital were used to inform a } \\
\text { multi-agency media campaign against burns associated with fireworks in } 2003 \text {. }\end{array}$ \\
\hline & Establishment of a Burn Treatment Unit \\
\hline & $\begin{array}{l}\text { Injury data collected at Benjamin Bloom Pediatric Hospital were used by the Ministry of Health to advocate for } \\
\text { national anti-gunpowder legislation, which was passed in } 2004 \text {. Combined with the } 2003 \text { gunpowder media } \\
\text { campaign, these efforts served as justification for the establishment of a Burn Treatment Unit at Bloom in } 2005 .\end{array}$ \\
\hline \multirow[t]{6}{*}{ Nicaragua } & Summer Prevention Plan \\
\hline & $\begin{array}{l}\text { The Ministry of Health led a nationwide multi-agency program to collect ED-based data on drowning, interpersonal } \\
\text { violence, and motor vehicle-related injuries in the summertime. Key elements included a comprehensive media } \\
\text { campaign and additional police patrols focusing on alcohol and speed. The effort integrated local police and fire } \\
\text { officials as well as staff from Nicaraguan hospitals, universities, and NGOs. }\end{array}$ \\
\hline & Bicyclist Injury Prevention Plan \\
\hline & $\begin{array}{l}\text { Program in León and Jinotepe that relied on ED-based injury data to promote road-safety education, helmet use, } \\
\text { and increased law enforcement activities. The program was supported by the Ministry of Health, national and local } \\
\text { police, Ministry of Transportation, Office of the Mayor, and several NGOs. }\end{array}$ \\
\hline & "Life Campaign" \\
\hline & $\begin{array}{l}\text { Data from the ED-based injury surveillance system were used to inform a multi-agency suicide prevention } \\
\text { campaign led by the Mental Health Department of the University of León. }\end{array}$ \\
\hline
\end{tabular}

retrospective review of national health data can provide evidence to support the development of such as system by highlighting the number of injury cases treated daily or yearly. Implementation of injury surveillance systems in three countries demonstrated that $18-36 \%$ of ED admissions were treated for an injury, with the highest percentages seen in urban hospitals.

The average number of daily injury cases captured by the injury surveillance system varied by country. For example, the system at two participating hospitals in Nicaragua captured 27482 injured patients over a 12-month period between 2001 and 2002, with injuries making up $27 \%$ of all hospital visits. A similar system at three hospitals in El Salvador captured just 18843 injuries in a 12-month period from 2003 to 2004, and reported that injuries accounted for $24 \%$ of all hospital visits.
A number of limitations make it difficult to compare data from injury surveillance systems between countries. These factors include differences in the demographics of participating hospital catchment areas; varying durations of data collection; and differences in hospital accessibility, the number of participating hospitals per country, and the availability of healthcare insurance.

\section{Integration with the Ministry of Health}

Initial coordination for the development of an injury surveillance system should be done with the national Ministry of Health epidemiology and planning/information units. In Nicaragua, the surveillance system was initiated under the Ministry of Health mental health unit because of the country's 
interest in suicide prevention. As the project evolved, the need for strong surveillance and data analysis expertise became evident. Oversight for the project then moved to the Ministry of Health epidemiology unit.

Similarly, in Colombia, initial project coordination did not include national Ministry of Health authorities but began at the Development and Research Institute in Violence Prevention and Social Promotion of Coexistence (Instituto de Investigación y Desarrollo en Prevención de Violencia y Promoción de la Convivencia Social, CISALVA) at Del Valle University, in conjunction with the Cali Municipal Health Department. As the Colombian project matured, securing national support became crucial for system sustainability. The project gained Ministry of Health support, even though Colombia has a decentralized health system in which program decisions and policies are made at the departmental (state) and municipality level. Even in a decentralized health system, the national Ministry of Health influenced local authorities' ability to maintain injury surveillance systems.

Surveillance system coordinators encouraged all stakeholders in injury prevention and control (national and local health organizations, hospitals, the police force, universities, health education institutions, and NGOs) to participate in local seminars and training. Early coordination among these partners engendered a multisectoral use of the data and a collaborative approach to injury prevention and control (Table 2).

\section{Limitations of hospital-based systems}

In both developing and developed countries, the catchment areas of hospitals are often ill defined, making it difficult to determine the population denominator needed to calculate injury rates. This was also true for the injury surveillance systems in Colombia, El Salvador, and Nicaragua. Despite this constraint, the population denominator must be considered in the planning stages of a hospital emergency department-based system; however, failure to define exact population figures should not preclude the establishment of an injury surveillance system. Similarly, an inherent limitation of a sentinel surveillance system is that only cases that present to a participating hospital are captured.

\section{Training}

The academic background of training participants in the field of epidemiology should be considered in the design of training courses. A basic understanding of epidemiologic concepts (particularly "data collection" and "data cleaning") was an important criterion for trainees responsible for data quality. Additionally, a one- to two-day "principles of epidemiology" course should be incorporated into the training curriculum for all participants. This course should include an overview of surveillance, data sources, variables and indicators, and public health applications.

Project training in Colombia, El Salvador, and Nicaragua relied on a combination of international and local lecturers. Local experts, identified by Ministry of Health officials, provided valuable perspectives on sensitive topics such as intimate partner violence, child maltreatment, and suicidal behavior. In addition, the inclusion of local experts created a sense of ownership and validated the importance of these local issues among trainees. International educators from CDC were useful in teaching local staff the basic elements of injury surveillance and epidemiology.

Training materials were tailored to local needs and interests and addressed injuries with high prevalence in each country. Two standardized injury training curriculums are now available for those looking to establish similar systems: CDC's Injury Surveillance Training Manual (27) published in English and Spanish, and WHO's Training, Educating, and Advancing Collaboration in Health on Violence and Injury Prevention (TEACH-VIP) Manual (28). These materials provide a flexible, structured, and comprehensive curriculum and include several different modules (e.g., "road traffic" and "data dissemination").

The surveillance systems relied on the incountry PAHO/CDC project coordinator to ensure that the project was integrated into standardized ED staff orientation and training. This ongoing training maintained and increased the acceptability of the data collection protocol.

\section{Data elements and collection instruments}

Several guidance documents recommend the standardization of injury surveillance data (18). To facilitate regional data sharing and coordination, minimum reporting variables should be based on international standards for data collection such as the ICECI (19). Colombia, El Salvador, and Nicaragua all agreed on an MDS common to all three countries prior to implementing their respective injury surveillance systems. The utility of using a simple, standardized set of internationally recognized definitions for injury surveillance has been demonstrated in several countries, including Honduras, Jamaica, and South Africa $(8,13,17)$. 
The two-page ED admission form used to collect injury data integrated both clinical and injury elements. The form replaced the ED clinical record to increase staff acceptance, a strategy based on lessons from an earlier injury surveillance system in León, Nicaragua (1992-1995).

\section{Monitoring and evaluation}

The ability of the in-country project coordinator to guide and recommend improvements of the system to participating hospitals was essential to project implementation. Project coordinators visited and evaluated hospitals weekly during the first month of the injury surveillance system and monthly over the following year. This allowed the coordinator to quickly address deficiencies in data collection methods, address any analysis concerns, and provide ongoing training as necessary. At the same time, each hospital monitored daily data collection for completeness and accuracy. The in-country $\mathrm{PAHO} / \mathrm{CDC}$ project coordinator evaluated data quality during site visits by sampling $5-10 \%$ of the records in the system for accuracy and completeness.

\section{Data dissemination}

Data dissemination must be rapid to ensure that it remains relevant and useful for both hospitals and external recipients. In Nicaragua, injury surveillance data were periodically published in the Nicaraguan Ministry of Health's Epidemiological Bulletin (21) and in peer-reviewed journals. In El Salvador, both the pediatric hospital and the regional trauma hospital published injury data in their hospital electronic bulletins. In Colombia, injury data were displayed on the hospital Web site and published in national journals $(25,26)$. All three countries presented results at national seminars and the World Injury Conferences in Montreal (2002); Vienna (2004); and Durban, South Africa (2006).

\section{Regional collaboration}

Sharing experiences and lessons among the pilot countries facilitates the improvement of data collection and analysis methods and protocols. In 2003, an injury conference in El Salvador led to a thorough reassessment of data elements used on the forms and resulted in a simpler data collection instrument. An evaluation of the system in Colombia in 2005 focused on missing data and hospital procedures related to training and data dissemination. Additional lessons and ideas were exchanged through site visits and conferences in Austria, Canada, Colombia, El Salvador, and the United States.

\section{Sustainability}

One of the core lessons expressed by a number of project participants was the need to obtain the support of the national Ministry of Health to ensure project sustainability. National support for an injury surveillance system improves if the data collection and analysis is coordinated within the Ministry of Health epidemiology unit. This has the additional benefit of initially involving key national stakeholders during the project implementation phase rather than after the system is already in place. In El Salvador, for example, the Ministry of Health has begun to include injury data from their ED-based injury surveillance system, the External Causes Injuries Information System (Sistema de Información de Lesiones de Causa Externa, SILEX), in a new national integrated electronic reporting health information system, the National Mortality Morbidity Health Information System (Sistema de Información Morbilidad-Mortalidad vía Web, SIMMOW). The same approach has been proposed in Colombia.

PAHO and the Ministry of Health in El Salvador have created an injury prevention program (Programa de Prevención de las Lesiones de Causa Externa) within the national epidemiological unit to provide leadership on national injury prevention strategies. Likewise, Nicaragua has appointed an epidemiologist at the national level dedicated to injury surveillance whose sole responsibility is the maintenance and expansion of the nationwide injury surveillance system. These examples provide evidence that recognition of injury as a public health priority and its integration into preexisting health information data systems can help increase the sustainability of surveillance programs.

Finally, partnerships with medical and public health schools provide both technical and leadership support in national medical and public health communities. In Colombia, the CISALVA Institute led the effort to translate WHO's violence-prevention training materials from English into Spanish and continues to offer a series of graduate-level courses on violence prevention. Similarly, León University has taken the lead in offering public health and injury-prevention training courses in Nicaragua.

\section{CONCLUSIONS}

The authors identified several lessons from the establishment of ED-based injury surveillance 
systems in Colombia, El Salvador, and Nicaragua that could be applicable to other developing countries. Highlights include the importance of collaboration with national and local partners, suggestions on best practices for training, and guidance to ensure system sustainability. Over the six years of pilot project implementation, injury data collected by Colombia, El Salvador, and Nicaragua have been used to structure interventions designed to improve public health outcomes. Future iterations of these interventions would benefit by integrating the core lessons of ED-based injury surveillance systems.

Acknowledgments. The authors thank Rebecca S. Noe, Linda L. Dahlberg, Mark Anderson, Susan Cookson, Gloria Suárez-Rangel, and CDC staff for research guidance and data review; F. Edgar Muñoz and Rafael Espinosa (in Colombia); Marieliz Rodríguez, Maribel Rivas, and Maribel Orozco (in Nicaragua); Gerardo de Cosio, Oscar Salinas, Jannette de Montoya, Rafael ChacónFuente, Antonio Tobar, Mercedes Menjivar, Tania Saballos, and Rubén Rodríguez (in El Salvador) for guidance and information on lessons learned and best practices; and the hospital data collection teams in all three participating countries.

Disclaimer. The findings and conclusions in this report are those of the authors and do not necessarily represent the views of the CDC.

\section{SINOPSIS \\ Establecimiento de sistemas de vigilancia de lesiones en Colombia, El Salvador y Nicaragua (2000-2006)}

La Organización Panamericana de la Salud (OPS), en colaboración con los Centros para el Control y la Prevención de Enfermedades (CDC) de los Estados Unidos de América, estableció en 2000 sistemas para la vigilancia de lesiones en Colombia, El Salvador y Nicaragua. Estos sistemas, basados en los servicios hospitalarios de emergencia, formaron parte de un proyecto piloto fundamentado en las guías para la vigilancia de lesiones, desarrolladas por la Organización Mundial de la Salud (OMS) y los CDC. Los objetivos de este proyecto eran evaluar la utilidad de las guías de la OMS/CDC, crear mecanismos apropiados para la vigilancia de lesiones en los tres países, promover intervenciones preventivas adecuadas e integrar la prevención y el control de lesiones en proyectos nacionales de salud pública. En este artículo se describe el proyecto piloto de la OPS/CDC y se resaltan los principios más importantes y las lecciones aprendidas durante sus seis años de funcionamiento (2000-2006). Entre las principales recomendaciones se encuentran la integración de la vigilancia de las lesiones en las unidades de epidemiología e información existentes en los ministerios de salud, la recogida de los datos importantes exclusivamente, la garantía de monitoreos y evaluaciones adecuados y la adopción de las prácticas que han demostrado ser más efectivas para el entrenamiento de personal y la diseminación de información.

Palabras clave: países en desarrollo, vigilancia sanitaria, vigilancia epidemiológica, Colombia, El Salvador, Nicaragua.

\section{REFERENCES}

1. World Health Organization. The World Health Report 2003. Annex 2: deaths by cause, sex and mortality stratum in WHO regions, estimates for 2002 [table on the Internet]. Geneva: WHO; 2003 [cited 2008 August 1]. Available from: http://www.who.int/whr/2003/annex/ en/index.html.

2. Peden M, McGee K, Sharma G. The injury chart book: a graphical overview of the global burden of injuries. Geneva: World Health Organization; 2002.

3. Smith GS, Barss P. Unintentional injuries in developing countries: the epidemiology of a neglected problem. Epidemiol Rev. 1991;13(1):228-66.

4. Rahman F, Andersson R, Svanström L. Potential of using existing injury information for injury surveillance at the local level in developing countries: experiences from Bangladesh. Public Health. 2000;114(2):133-6.

5. Langley J. Challenges for surveillance for injury prevention. Inj Control Saf Promot. 2004;11(1):3-8.
6. Langley JD. The role of surveillance in reducing morbidity and mortality from injuries. MMWR Morb Mortal Wkly Rep. 1992;41 Suppl:181-90.

7. Stokes M, van Leeuwen P, OzanneSmith J. The use of injury surveillance databases to identify emerging injury hazards. Int J Inj Contr Saf Promot. 2005; 12(1):1-7.

8. Ashley D, Holder Y. The Jamaican Injury Surveillance System: lessons learnt. Inj Control Saf Promot. 2002;9(4):263-4.

9. Forjuoh SN, Gyebi-Ofosu E. Injury surveillance: should it be a concern to developing countries? J Public Health Policy. 1993;14(3):355-9.

10. Graitcer PL. Injury surveillance in developing countries. MMWR Morb Mortal Wkly Rep Surveill Summ. 1992;4(1): 15-20.

11. Rahman F, Ali Y, Andersson R, Svanström L. Epidemiology of injury: results from injury registration at a district level hospital in Bangladesh-implications for prevention in low-income countries. Inj Control Saf Promot. 2001;8(1):29-36.

12. Hang HM, Ekman R, Bach TT, Byass P, Svanström L. Community-based assessment of unintentional injuries: a pilot study in rural Vietnam. Scand J Public Health. 2003;31(1 Suppl 62):38-44.

13. Richman M, Shayne P, Heron S, Lowery $\mathrm{D}$, Todd $\mathrm{KH}$. Injury control in Honduras: a survey of injury mortality. Ann Emerg Med. 2000;36(4):333-9.

14. Tercero F, Andersson R, Rocha J, Castro $\mathrm{N}$, Svanström L. On the epidemiology of injury in developing countries: a oneyear emergency room-based surveillance experience from León, Nicaragua. Inj Control Saf Promot. 1999;6(1):33-42.

15. Espitia-Hardeman V, Rocha J, ClavelArcas C, Dahlberg L, Mercy JA, ConchaEastman A. Characteristics of non-fatal injuries in Leon, Nicaragua-2004. Int J Inj Contr Saf Promot. 2007;14(2):69-75.

16. London J, Mock C, Abantanga FA, Quansah RE, Boateng KA. Using mortu- 
ary statistics in the development of an injury surveillance system in Ghana. Bull World Health Organ. 2002;80(5): 357-64.

17. Butchart A, Peden M, Matzopoulos R, Phillips R, Burrows S, Bhagwandin N et al. The South African National NonNatural Mortality Surveillance Systemrationale, pilot results and evaluation. S Afr Med J. 2001;91(5):408-17.

18. Holder Y, Peden M, Krug E, Lund J, Gururaj G, Kobusingye O, editors. Injury surveillance guidelines. Geneva: World Health Organization; 2001. pp. 1-92. (WHO/NMH/VIP/01.02).

19. World Health Organization; National Institute for Public Health and the Environment (RIVM). WHO Family of International Classifications (FIC). International Classification of External Causes of Injuries (ICECI) [classification tool on the Internet]. Version 1.2 (July 2004). Geneva: WHO; 2004 [cited 2008 August 1]. Available from: http://www.rivm. $\mathrm{nl} /$ who-fic/ICECleng.htm.

20. Noe R, Rocha J, Clavel-Arcas C, Aleman C, Gonzales ME, Mock C. Occupational injuries identified by an emergency department based injury surveillance system in Nicaragua. Inj Prev. 2004;10(4): 227-32.

21. Ministry of Health (NI). Sistema de Vigilancia de Lesiones de Causa Externa. Semana Epidemiológica [serial on the Internet]. $2003 \mathrm{Feb}$ [cited $2008 \mathrm{Au}-$ gust 1];(6): [about 4 p.]. Available from: http://www.minsa.gob.ni/vigepi/ $\mathrm{html} /$ boletin/2003/editorial06.html.

22. Concha-Eastman A, Villaveces A. Guidelines for the epidemiological surveillance on violence and injuries. Washington: Pan American Health Organization; 2001. (HCP/HCN/01.01).

23. German RR, Lee LM, Horan JM, Milstein RL, Pertowski CA, Waller MN; Guidelines Working Group, Centers for Disease Control and Prevention (CDC). Updated guidelines for evaluating public health surveillance systems. MMWR Recomm Rep. 2001;50(RR-13):1-35.

24. Hospital Nacional de Niños Benjamin Bloom (SV) [homepage on the Internet]. San Salvador: HNNBB; 2007 [cited 2008
August 1]. Available from: http:// www.hospitalbloom.gob.sv.

25. Bejarano M, Rendón LF, Rojas MC, Durán CA, Albornoz M. Caracterización de los pacientes con lesiones de causa externa mediante un sistema de vigilancia epidemiológica. Rev Colomb Cir. 2006;21(3):180-9.

26. Bejarano M, Rendón LF, Rojas MC, Durán CA, Albornoz M. Factores asociados con la intencionalidad en las lesiones de causa externa. Rev Colomb Cir. 2006;21(4):215-24.

27. Espitia-Hardeman V, Paulozzi L. Injury Surveillance Training: instructor manual and participants guide [CD-ROM]. Atlanta (GA): National Center for Injury Prevention and Control, Centers for Disease Control and Prevention; 2005.

28. TEACH-VIP (Training, Educating and Advancing Collaboration in Health on Violence and Injury Prevention): user's manual and CD-ROM [training materials]. Geneva: World Health Organization; 2005. 